\title{
Development and validation of a sensitive reversed phase HPLC method to determine total, free drug and encapsulation efficiency of cytotoxic Nano pharmaceutical
}

\author{
Shripad Deshpande ${ }^{1 *}$, Mazahar Farooqui ${ }^{2}$, \\ Gajanan Sanap ${ }^{1}$, D.D. Kayande ${ }^{1}$ \\ ${ }^{1}$ S.B.E.S.College of Science, Aurangabad, India \\ ${ }^{2}$ Dr.Rafiq Zakaria College for Women, Aurangabad, India
}

\begin{abstract}
The intracellular accumulation of anti-cancer agents strongly influences the efficiency of chemotherapy for cancer. In the present research work, a simple rapid, sensitive reversed-phase high performance liquid chromatographic (RP-HPLC) method was developed and validated to determine free, encapsulated and total drug in Doxorubicin liposome a cytotoxic Nano pharmaceutical formulation. The free drug and total drug were measured by RP-HPLC with a C18 column after extraction with waters Oasis SPE cartridge using solid phase extraction assembly with methanol and mobile phase as diluent. The mobile phase contained $0.1 \%$ trifluro acetic acid and solvent mixture of acetonitrile and methanol in the ratio of 80:20. UV/PDA detector with wavelength $254 \mathrm{~nm}$ was used for determination of free and encapsulated drug. The calibration curve was linear from 5 to $100 \mu \mathrm{g} / \mathrm{ml}$ with correlation coefficient of 0.999 while the recovery of total assay was between $98 \%$ and $101 \%$. The intra and inter day coefficient of variation (RSD) were less than $1 \%$. Furthermore, the validated method was used to determine the free, encapsulated and total drug for the developmental liposome as Nano pharmaceutical formulation.
\end{abstract}

Keywords:HPLC,Doxorubicin Liposomes, validation, freedrug, Encapsulation efficiency.

\section{Introduction:}

Cancer is one of the leading causes of death worldwide. Cancer cell proliferate at much faster rate than the normal cell. The available cancer chemotherapy is not selective as it depends on the kinetics of the cell growth. As the liposome are target specific, more effective and beneficiary in comparison to available chemotherapy treatment procedure. Liposomes have ability to encapsulatedifferent materials, together withadvances in liposome technology; it has given rise to the relatively recent use ofliposomes as vehicles to incorporateactive agents into systems. These processes, which areknown as liposome delivery systems(LDSs), have shown remarkableprogressin past few years, otherapplications of liposomal encapsulationare also being developed in food andnutrition industries to improve theantioxidant additives ${ }^{1-3}$.Liposomes are small microscopic vesicles formed by phospholipids dispersed in water. When amphipathic lipid molecules containing

Shripad Deshpande et al /International Journal of PharmTech Research, 2019,12(1): 69-79.

DOI: http://dx.doi.org/10.20902//JPTR.2019.120110 
polar heads and hydrophobic hydrocarbon tails are suspended in an aqueous buffer medium, they can associate spontaneously to form bilayer vesicles. The basic structure of liposomes is similar to biologicalcell membranes, in which hydrocarbon chains are orientated towards each other and polar head groups are in contact with encapsulated and surrounding aqueous buffer medium. The resulting vesicles comprise an aqueous compartment surrounded by one or more lipid bilayers, which are relatively impermeable to the entrapped substances $^{4-5}$.Liposome structure is determined by the nature of the ingredients used and the interactions between the lipid bilayer and the aqueous buffer medium during its formation. Liposomeshave different sizes, with different diameters ranging from few $\mathrm{nm}$ to many $\mu \mathrm{m}$,it will provide excellent ways to encapsulate different materials. Both water soluble and lipid-soluble substances may be incorporated into the aqueous and lipid phases of liposomes, respectively. Liposomes and/or their ingredients are the objects of the analytical determination. Size makes the most obvious difference between Nano pharmaceutical products and conventional medicinal product. Indeed, liposome size distribution is identified as one of the key parameters determining the bio distribution ${ }^{6}$.Doxil is the trade name for doxorubicin liposomal. In some cases, health care professionals may use the trade name doxil when referring to the generic drug name Doxorubicin (liposomal) is an anti-cancer ("antineoplastic" or "cytotoxic") chemotherapy drug. It is the drug doxorubicin encapsulated in a closed lipid sphere (liposome). This medication is classified as an "anthracycline antibiotic There is PEG (polyethylene glycol coated) liposome-encapsulated form of doxorubicin, sold as Doxil. It was developed to treat Kaposi's sarcoma, an AIDS-related cancer that causes lesions to grow under the skin, in the lining of the mouth, nose and throat, or in other organs. The polyethylene glycol coating results in preferential concentration of doxorubicin in the skin. Because liposome-encapsulated doxorubicin is less cardio toxic than encapsulated doxorubicin. This form is also approved by the FDA for treatment of ovarian cancer and multiple myelomaDoxorubicin other hand, has an advantage over its camptothecin precursors in that it does not require activation by the liver, thereby greatly reducing the interpatient variability ${ }^{7-8}$. Novel/Controlled drug delivery system represents one of the broader areas of science, which involves multidisciplinary scientific approach, contributing to human health care and pharmaceutical development ${ }^{9}$. Drug targeting is defined as a selective drug release at specific physiological sites, cells, tissues, organs or in which the pharmacological effect is required. The concept of drug targeting is used in attempts to improve the therapeutic index and efficacy of drugs by increasing their localization to specific organs, tissues or cells and by decreasing their potential toxic, side and adverse effects at normal sensitive sites ${ }^{10-11}$. The efficacy of many drugs is often limited by their potential to reach the site of therapeutic action. In most cases (conventional dosage forms), only a small amount of administered dose reaches the target site, while the Chemotherapy has become an integral component of cancer treatment for most cancers. Conventional chemotherapeutic agents still exhibit poor specificity in reaching tumor tissue and are often restricted by dose-limiting toxicity. The combination of developing controlled release and targeted drug delivery may provide a more efficient and less harmful solution to overcome the limitations found in conventional chemotherapy. The efficacy of cancerous chemotherapy is often limited by serious side effects because of the toxicity of anticancer drugs to both tumor and normal cells ${ }^{12-13}$. In targeted cancer therapy, conventional chemotherapeutic agents, which lack specificity, are rationally modified to focus and redirect their cytotoxicity to tumor cells. Themechanism of action of Doxorubicin Hydrochloride is thought to be related to itsability to bind DNA and inhibit nucleic acid synthesis. The liposomes have a half-life of approximately 55 hours. They are stable in blood. As it having less size and persistence in the circulation they are able to penetrate the altered and often compromised vasculature of tumors having size $100-780 \mathrm{~nm}$.

To support on-going formulation development and other preclinical studies in industries, a specific, sensitive and time saving and cost effective RP-HPLC analytical method is developed by taking different trial experiments and finally developed method is validated for determination offree, total and/or encapsulated drug in liposomes. As of now only there is guidance for industry for Liposome drug Products and no any pharmacopeia official liposomal product available. The available literature is patchy, required non-conventional analytical methods and also there is non-availability of free drug determination method. A freeand total drug method was developed by using the solid phase extraction assembly and syringe-barrel-type cartridges. Which has a polymeric reversed-phase sorbent and that will extract acidic, basic and neutral compounds. The basic method development initiation was carried out by considering the USP monograph available for Doxorubicin hydrochloride injection in US pharmacopeia. The current study is mainly focused on Doxorubicin liposome preparation, basic characterization for size,shape,morphology,and a new validated analytical method for free drug and total drug determination for prepared pegylated liposome formulation. 


\section{Materials and Equipment's:}

Trifluroacetic acid was purchased from SIGMA-ALDRICH. Acetonitrile and Methanol were purchased from Merck. Purified water was obtained from Milli-Q water system (Millipore Corp). Sodium hydroxide and $36 \%$ Hydrochloric acid was purchased from Merck. Hydrogen peroxide (30\%) was purchased from Merck. WATERS Oasis 1 CC cartridge was gifted from waters and is used for research work. Solid phase extraction assembly from Waters used for extraction study. Ammonium chloride was purchased from Merck. All chemicals were used as such and provided by manufacturer, no further purification has been done. All the other chemicals were of analytical grade. Magnetic stirrer, cyclomixer, micro centrifuge bought from Eppendorf Equipments Pvt. Ltd. was used. HPLC from Agilent, used in the analysis of drug. A bath sonicator from PCI Analytics brand was used.

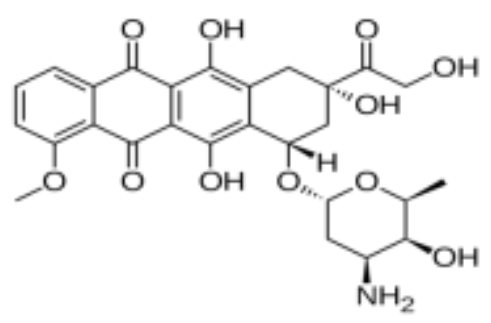

\section{Fig. 1. Structure of Doxorubicin.}

\section{Chromatographic system and condition:}

The HPLC system consists of an Agilent 1100 module, including quaternary pump,auto-sampler with thermostat, column oven, coupled with a multiple wavelength or diode array UV detector. Thrmo Hypersil BDS-C18 $(4.6 \mathrm{~mm} \times 100 \mathrm{~mm}, 3 \mu)$ and Agilent Zorbax C18 $(4.0 \mathrm{~mm} \times 150 \mathrm{~mm}, 5 \mu)$ analytical columns were used for method development and validation. The Ezchrome Elite(Open lab) chromatographic Software was used for data acquisition and processing. The mobile phase consisted of a mixture of Mobile phase a) $0.1 \%$ trifluroacetic acid and moblile phase b) solvent mixture (acetonitrile:Methanol in the ratio of 80:20) (65:35, v/v\%). During total drug assay, an aliquot of $20 \mu \mathrm{L}$ of diluted sample of liposome-based Doxorubicin was injected in duplicate into the analytical column at $40{ }^{\circ} \mathrm{C}$ at a flow rate of $1 \mathrm{~mL} / \mathrm{min}$. Doxorubicin was detected at $254 \mathrm{~nm}$ and quantitatively determined. The analytical column theoretical plate number and tailing factor of the analytes under different chromatographic conditions were calculated using USP methods.

\section{Preparation of Multilamellar Vesicles (MLV):}

Prior to weighing,lipid brought to room temperature DSPE-MPEG $(3.19 \mathrm{mg} / \mathrm{mL})$, Lecithin $(9.58$ $\mathrm{mg} / \mathrm{mL})$, cholesterol $(3.19 \mathrm{mg} / \mathrm{mL})$ and ammonium sulphate $(2 \mathrm{mg} / \mathrm{mL})$ were used for preparation of liposome. Transferred lipid content to a round bottom flask, Initially all lipids dissolved in highly pure grade chloroform solvent in this preparation $1 \mathrm{~mL}$ of solvent used. Pure grade chloroform is used to avoid contamination by impurities.After complete solubility of lipids the solvent removed completely by applying vacuum to round bottom flask. After complete evaporation of solvent the lipid sample assume a dried white fluffy appearance to obtain a maximal surface area for hydration.

\section{Lipid Hydration:}

The dried lipid is then hydrated by intermittently vortexes during 5 minutes hydration process with phosphate buffer saline $\mathrm{pH}$ 4.5.The resulting multilamellar vesicles are very heterogeneous and ranging from $500 \mathrm{~nm}$ to several micrometres. The size of MLV measured by Malvern Zeta sizer. In order to reduce the size of MLV probe sonicator is used.The MLV are subjected for sonication after each 5 minutes of interval the size was checked and sonication was continued till to achieve the desired size ranging from (100-120nm).

\section{Encapsulation Doxorubicin:}

The $2 \mathrm{mg} / \mathrm{mL}$ of doxorubicin and liposome are individually incubated at $60^{\circ} \mathrm{C}$ for 30 minutes. This temperature is typically selected to give greater than $95 \%$ loading. Reached the specific temperature the doxorubicin is rapidly added to the prepared liposomes and vortexes intermittently during the incubation time. 


\section{Characterization of PEG-Doxorubicin liposome asNanoparticles:}

\section{Particle size, Zeta Potential}

In order to examine the particle surface morphology and shape, scanning electron microscopy (SEM) was used. A PEG-Doxorubicin nanoparticles solution was spread over a slab and dried under vacuum. were shadowed in a cathodic evaporator with gold layer 20nm thick photograph were taken using a JSM-5200 SEM (Toky, Japan) operated at $20 \mathrm{Kv}$. The electrophoretic mobility and zeta potential were measured using a zeta potentiometer (Malvern Zeta sizer). To determine the zeta potential, nanoparticles sample were diluted with $\mathrm{KCl}$ $(0.1 \mathrm{~mm})$ and placed in the electrophoretic cell where an electric field of $15.2 \mathrm{~V} / \mathrm{cm}$ was applied. Sample was analysed in triplicate.

\section{Free Drug determination:}

Free drug was determined by the solid phase extraction method using WATERS OASIS 1 CC Cartridge. Initially washed the cartridge with $1 \mathrm{~mL} 0.1 \mathrm{M}$ ammonium chloride then wash same cartridge with 2 $\mathrm{mL}$ of methanol. Transferred $1 \mathrm{ml}$ of sample into the WATERS OASIS 1 CC Cartridge with the pipette and extract the free drug with the help of solid phase extraction assembly using $10 \mathrm{~mm} \mathrm{Hg}$. Pressure under vacuum. The cartridge washed with $4 \mathrm{~mL}$ water four times, the free drug trapped on the cartridge is washed with $4 \mathrm{~mL}$ methanol and transferred content in $10 \mathrm{~mL}$ volumetric flask, make up to the mark with mobile phase.

\section{Total Drug determination:}

Transfer content of vial in a dry test tube.Pipette out $1 \mathrm{~mL}$ of Doxorubicin $\mathrm{HCl}$ liposomal sample (2 $\mathrm{mg} / \mathrm{mL}$ ) into a clean and dry $10 \mathrm{~mL}$ volumetric flask, added $4 \mathrm{~mL}$ of methanol and sonicate for 3 minutes,further dilute to the mark with methanol. Transferred $5 \mathrm{~mL}$ of this solution to $20 \mathrm{~mL}$ volumetric flask and made up to mark with mobile phase.

\section{$\%$ encapsulated drug assay $=(\%$ Total Assay $-\%$ free drug assay $)$}

\section{Method validation:}

\section{Specificity and force degradation:}

To assure the specificity of the current method, the liposome formulation placebo containing the same concentration of lipids and other excipients as in the active formulation was evaluated. Forced-degradation experiments were also performed on the liposome formulation samples under different stressed conditions. The stress conditions used were acid $(1 \mathrm{~N} \mathrm{HCl}, 30$ minutes at room temperature) and alkali $(0.1 \mathrm{~N} \mathrm{NaOH}$, less than one minutes at room temperature) treatments and oxidation $(30 \% \mathrm{H} 2 \mathrm{O} 2,30$ minutes at room temperature). Similarly photolytic and Humidity stress study also performed. The percentage of degradation under each stressed condition were chromatographically baseline separated under the HPLC conditions. Under alkali condition $(0.1 \mathrm{~N} \mathrm{NaOH})$, liposome formulation degraded about $12 \%$ and observed that it is extremely unstable to alkaline hydrolysis.it generated an unknown degradant. Similarly it is also observed that it is unstable to oxidation at room temperature. There is less degradation observed in acid and photolytic degradation compare to alkaline and oxidative stress conditions. Results are tabulated in (Table-1).

\section{Linearity:}

The relationship between Doxorubicin $\mathrm{HCl}$ concentration and detector response was evaluated to confirm linearity. Doxorubicin $\mathrm{HCl}$ standards at Ten different concentrations encompassing minimum of 80$120 \%$ of the expected concentration of Doxorubicin $\mathrm{HCl}$ in Doxorubicin liposome were included in the study. It was found that in the concentration range of $5-100 \mu \mathrm{g} / \mathrm{mL}$, the detector response of Doxorubicin $\mathrm{HCl}$ was linear with a correlation coefficient greater than 0.9991.(Table-2).

\section{Accuracy (Spike recovery):}

The Doxorubicin $\mathrm{HCl}$ spike samples were prepared by the addition of Doxorubicin HClAPI to the liposome placebos at $80 \%, 100 \%$ and $120 \%$ of the expected concentrationof Doxorubicin $\mathrm{HCl}$ in DoxorubicinHClliposome. The average percent recoveries of DoxorubicinHCl in the spiked samples at three 
different levels ranged from $98.6 \%$ to $100.7 \%$ with an overall average of $99.3 \%$.The percent of relative standard deviation (\%RSD) for the triplicate measurements at each level was less than $0.8 \%$ (Table-5),which demonstrated a high level ofaccuracy.

\section{Precision:}

The precision of the analytical method was evaluated by system precision, repeatability (intra-day) and intermediate precision (inter-day).The repeatability was done by analysing six samples of Doxorubicin $\mathrm{HCl}$ liposome (duplicate injection of each). The same process was repeated on the second day to assess intermediate precision using six freshly prepared sample solutions. The precision was measured by the \%RSD of the duplicate injections for each of the six samples. It was found that the system precision was $0.52 \%$ on day-1.The method precision was $0.53 \%$ on day- 1 and $0.50 \%$ on day- 2 these data demonstrated the acceptable precision of the method. (Table $-3,4$ and 7).

\section{Robustness:}

The robustness of the analytical method was assessed by analysing HPLC system suitability using a Doxorubicin $\mathrm{HCl}$ standard $(50 \mu \mathrm{g} / \mathrm{mL}$, five replicate injections) under deliberately altered conditions including changes in column temperature, analytical method flow rate and solution filtered conditions. The resulting retention time and system suitability parameters, such as theoretical plate number, detector response (peak area) and tailing factor under each changed condition are shown in Table- 6 changes in column temperature by $\pm 5^{\circ} \mathrm{C}$ had no impact on retention time, detector response and tailing factor. Mobile phase flow rate had expected effects on doxorubicin retention time, detector response and tailing factor. As the mobile phase flow rate was decreased to $0.8 \mathrm{~mL} / \mathrm{min}$, the Doxorubicin retention time was increased, theoretical plate number and detector response decreased. When the flow rate was increased to $1.2 \mathrm{~mL} / \mathrm{min}$, the Doxorubicin retention time was decreased, theoretical plate number and detector response increased. It was observed that changing the flow rate from 0.8 to $1.2 \mathrm{~mL} / \mathrm{min}$ had little effect on the tailing factor. Overall, under various deliberately altered HPLC conditions, the method demonstrated sufficient ruggedness and is considered acceptable for the analysis of DoxorubicinPeak.

\section{Results and Discussions:}

A simple HPLC method having short run time was developed and validated for determination of free drug, total drug and encapsulation efficiency of Doxorubicin $\mathrm{HCl}$ in the novel, PEG-liposome based formulations. Even though Doxorubicin $\mathrm{HCl}$ was formulated in a complex phospholipids matrix, the current method involved sample pre-treatment or extraction procedures for free drug determination. For total drug only a drug simple dilution of the formulation prior to HPLC analysis was required. The method validation results indicate that the method is specific, linear, accurate, precise, robust and sensitive that is suitable for determination of Doxorubicin concentration and drug encapsulation efficiency in liposomes to support formulation development.

Table No. 1: Specificity for Doxorubicin Hydrochloride

\begin{tabular}{|l|l|l|l|l|}
\hline Sr.No. & Name of the solution & No. of injection & Retention time & Total purity \\
\hline 1 & Blank & 1 & NA & NA \\
\hline 2 & Placebo & 1 & NA & NA \\
\hline 3 & Standard solution & 1 & 4.21 & 1.0000 \\
\hline 4 & Sample solution & 1 & 4.19 & 1.0000 \\
\hline
\end{tabular}


Blank:

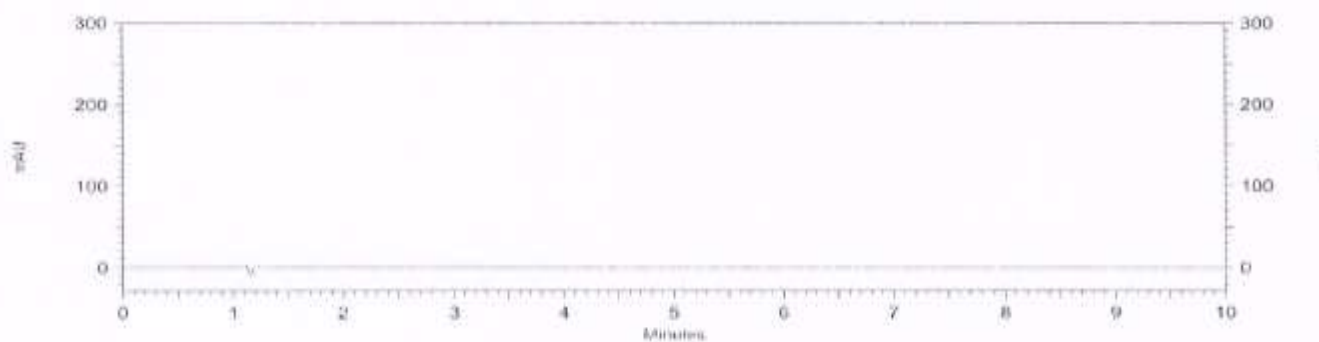

Fig No.1: Blank chromatogram:

Placebo:

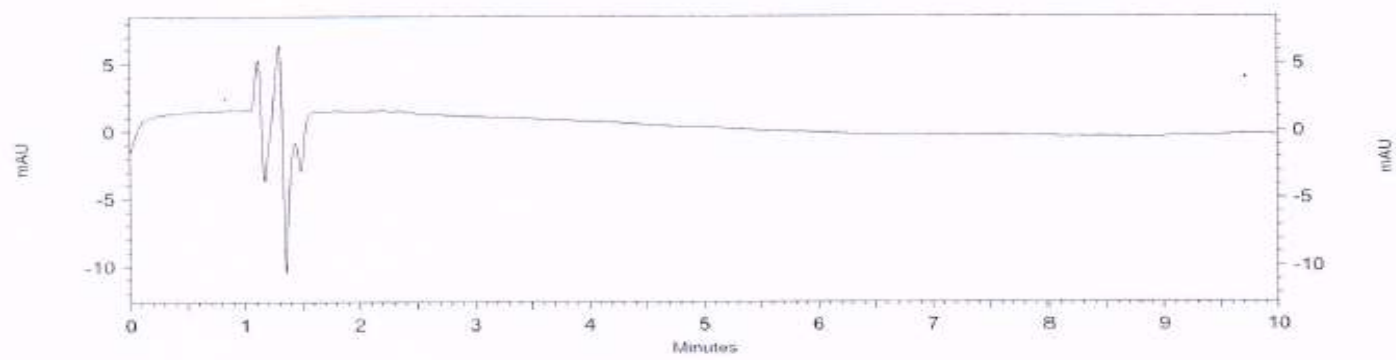

Fig No.2: Placebo chromatogram

Standard solution_1:

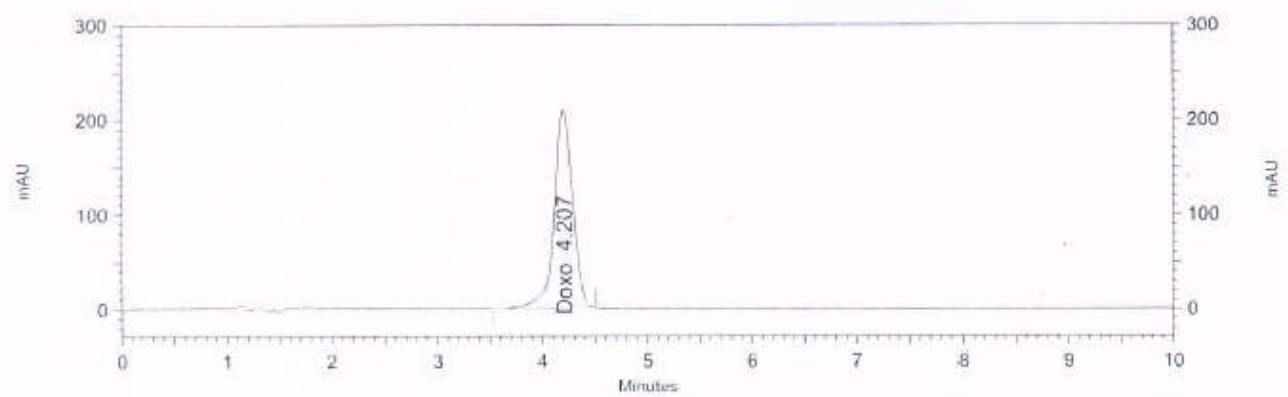

Fig No.3: Standard chromatogram

Method precision sample_1:

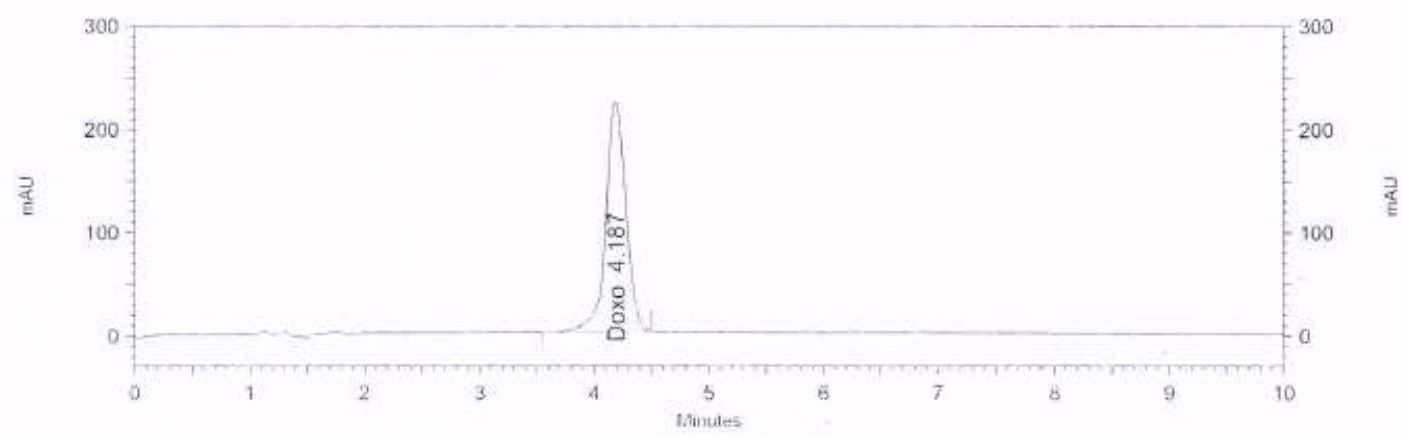

Fig No.4: Sample chromatogram 


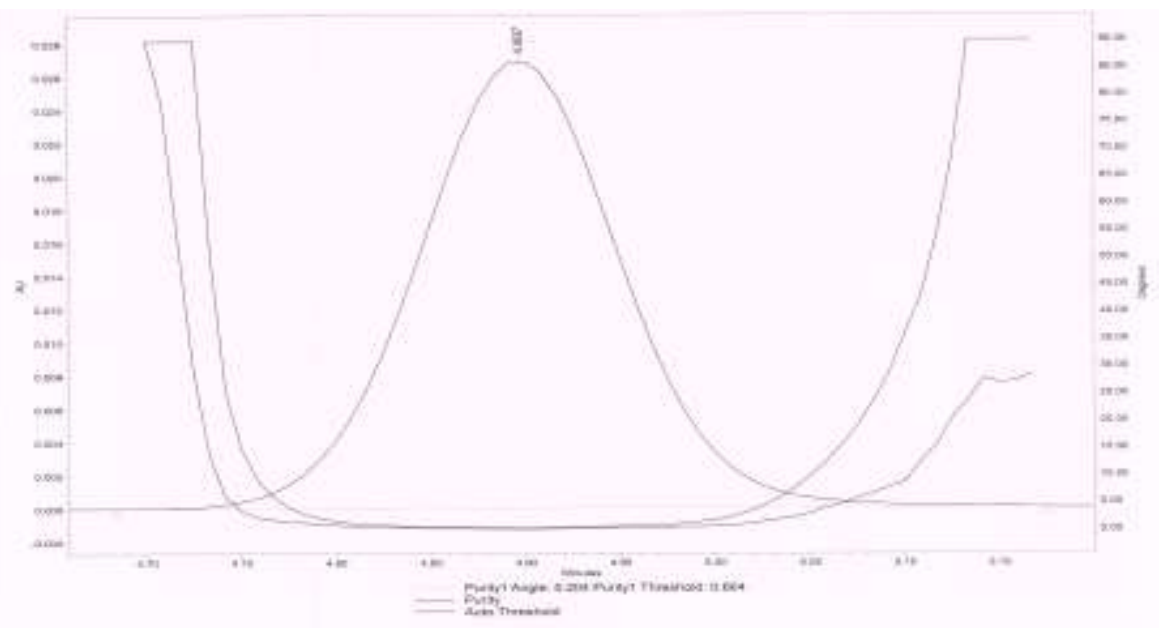

Fig No.5: Spiked sample chromatogram for peak purity.

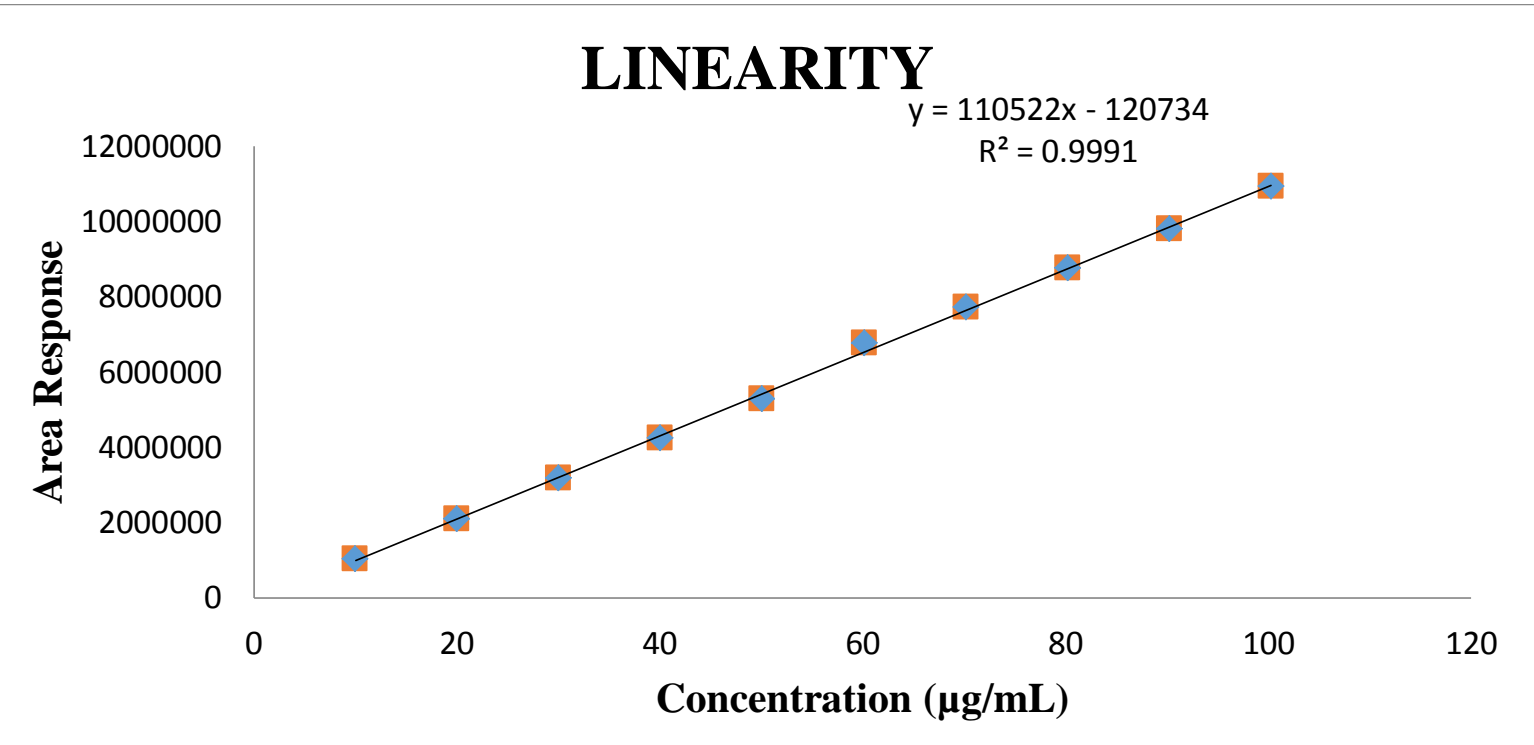

Fig No.6: Linearity plot for Doxorubicin HCl.

Table No. 2: Linearity of response for Doxorubicin Hydrochloride

\begin{tabular}{|c|c|c|c|c|c|}
\hline Sr. No. & $\begin{array}{l}\text { Target level } \\
(\%)\end{array}$ & $\begin{array}{l}\text { Concentration } \\
(\mu \mathrm{g} / \mathrm{mL})\end{array}$ & Area-1 & Area-2 & Average area \\
\hline 1 & 10 & 10.03 & 1023047 & 1017642 & 1020345 \\
\hline 2 & 20 & 20.06 & 2084725 & 2098541 & 2091633 \\
\hline 3 & 30 & 30.09 & 3183587 & 3166830 & 3175209 \\
\hline 4 & 40 & 40.12 & 4232491 & 4236687 & 4234589 \\
\hline 5 & 50 & 50.15 & 5288653 & 5276074 & 5282364 \\
\hline 6 & 60 & 60.18 & 6763699 & 6772301 & 6768000 \\
\hline 7 & 70 & 70.21 & 7720793 & 7709330 & 7715062 \\
\hline 8 & 80 & 80.24 & 8856836 & 8643439 & 8750138 \\
\hline 9 & 90 & 90.27 & 9800044 & 9792343 & 9796194 \\
\hline 10 & 100 & 100.3 & 10942967 & 10914399 & 10928683 \\
\hline \multicolumn{5}{|c|}{ Slope } & 110522.2 \\
\hline \multicolumn{5}{|c|}{ Intercept } & -120734 \\
\hline
\end{tabular}




\begin{tabular}{|l|l|}
\hline$\%$ Y-intercept & -2.28561 \\
\hline Residual sum of square & 108823.7 \\
\hline Correlation coefficient & 0.9995 \\
\hline $\mathbf{R}^{2}$ & 0.9991 \\
\hline
\end{tabular}

Table No. 3: Precision- System precision for Doxorubicin Hydrochloride

\begin{tabular}{|c|c|c|c|c|c|c|}
\hline $\begin{array}{l}\text { Sr. } \\
\text { No. }\end{array}$ & $\begin{array}{l}\text { Standard_1 } \\
\text { response }\end{array}$ & $\begin{array}{ll}\begin{array}{l}\text { Standard_2 } \\
\text { response }\end{array} & \text { area } \\
\end{array}$ & $\begin{array}{l}\text { Mean area from } \\
\text { standard_1 }\end{array}$ & SD & $\%$ RSD & $\begin{array}{l}\text { Similarity } \\
\text { Factor }\end{array}$ \\
\hline 1 & 5352648 & 5338268 & \multirow{5}{*}{5304469} & \multirow{5}{*}{27413.4} & \multirow{5}{*}{0.52} & \multirow{5}{*}{100.0} \\
\hline 2 & 5293893 & 5350517 & & & & \\
\hline 3 & 5285049 & & & & & \\
\hline 4 & 5291474 & & & & & \\
\hline 5 & 5299283 & & & & & \\
\hline
\end{tabular}

Table No. 4: Method Precision-Repeatability for Doxorubicin Hydrochloride

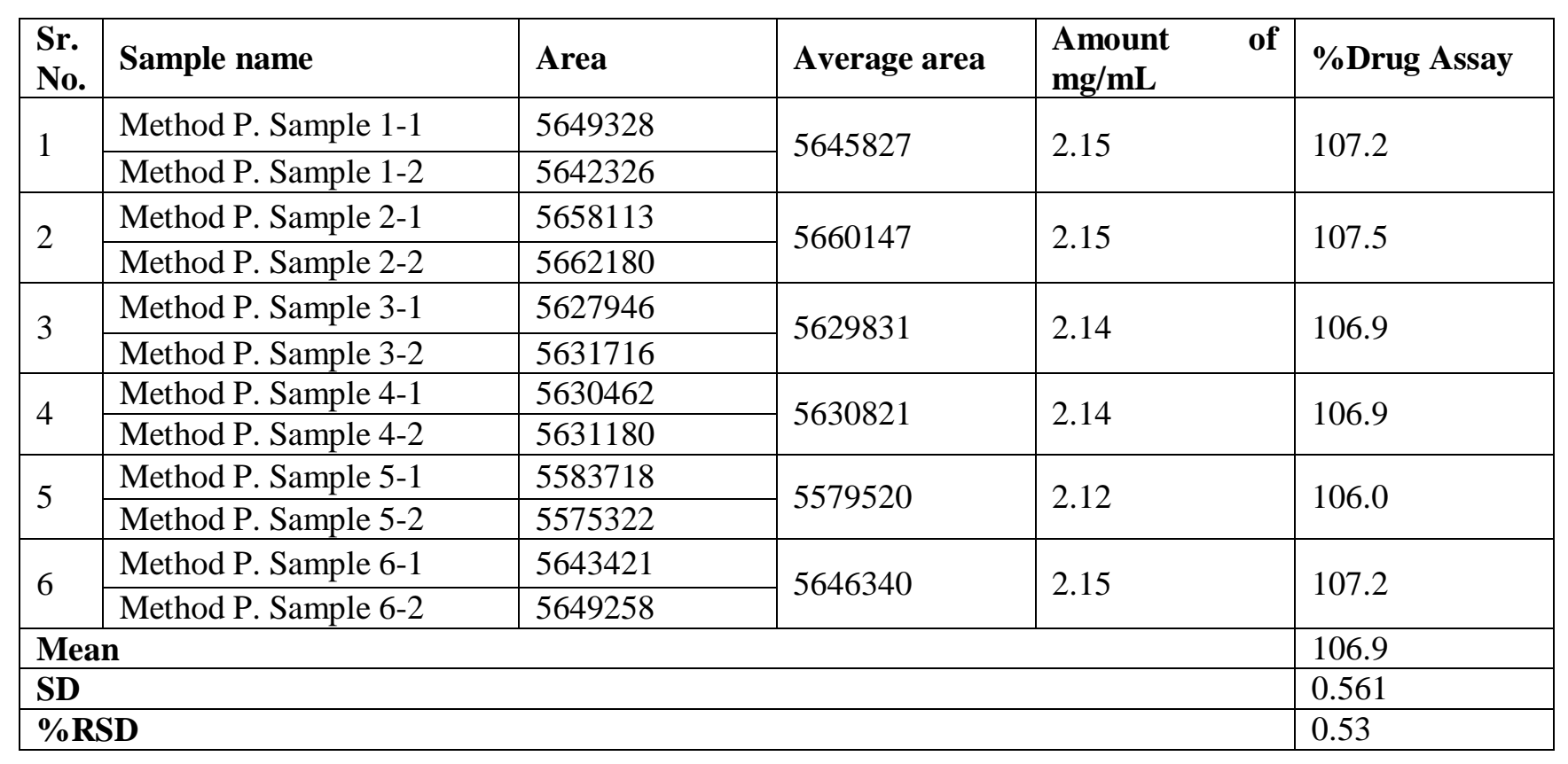

Table No. 5: Accuracy for Doxorubicin Hydrochloride

\begin{tabular}{|l|l|l|l|l|l|}
\hline $\begin{array}{l}\text { Sr. } \\
\text { No. }\end{array}$ & Target level & $\begin{array}{l}\text { Average } \\
\text { Area }\end{array}$ & $\begin{array}{l}\text { Amount drug added } \\
(\boldsymbol{\mu g} / \mathbf{m L})\end{array}$ & $\begin{array}{l}\text { Amount drug found } \\
(\boldsymbol{\mu g} / \mathbf{m L})\end{array}$ & \% Recovery \\
\hline 1 & $80 \%$ sample-1 & 4247375 & 40.3 & 40.42 & 99.7 \\
\hline 2 & $80 \%$ sample-2 & 4196304 & 40.225 & 39.93 & 100.7 \\
\hline 3 & $80 \%$ sample-3 & 4216668 & 39.925 & 40.175 & 99.4 \\
\hline 4 & $100 \%$ sample-1 & 5353314 & 50.275 & 50.94 & 98.7 \\
\hline 5 & $100 \%$ sample-2 & 5389155 & 50.475 & 51.28 & 98.4 \\
\hline 6 & $100 \%$ sample-3 & 5282534 & 49.95 & 50.27 & 99.4 \\
\hline 7 & $120 \%$ sample-1 & 6843378 & 64.475 & 65.11 & 99.0 \\
\hline 8 & $120 \%$ sample-2 & 6635353 & 62.475 & 63.14 & 98.9 \\
\hline 9 & $120 \%$ sample-3 & 6710139 & 63.575 & 63.85 & 99.6 \\
\hline Mean & & & & 99.3 \\
\hline SD &
\end{tabular}


Table No. 6: Robustness of Doxorubicin Hydrochloride

\begin{tabular}{|l|l|l|l|l|l|l|l|l|}
\hline Sr.No. & Parameter & Variation & RT(min) & $\begin{array}{l}\text { Area-1 } \\
(\text { mean) }\end{array}$ & $\begin{array}{l}\text { Area-2 } \\
(\text { mean) }\end{array}$ & Similarity & SD & \%RSD \\
\hline \multirow{2}{*}{1} & \multirow{2}{*}{ Flow rate } & $-20 \%$ & 5.11 & 5873590 & 5977052 & 99.0 & 17381.56 & 0.3 \\
\cline { 3 - 9 } & $+20 \%$ & 3.47 & 4602142 & 4670471 & 99.3 & 28965.46 & 0.6 \\
\hline \multirow{2}{*}{2} & $\begin{array}{l}\text { Column } \\
\text { temperature }\end{array}$ & $-5^{\circ} \mathrm{C}$ & 3.69 & 4579407 & 4658114 & 99.1 & 12928.08 & 0.3 \\
\cline { 3 - 9 } & $+5^{\circ} \mathrm{C}$ & 3.10 & 4549209 & 4661000 & 98.4 & 44293.30 & 1.0 \\
\hline
\end{tabular}

Table No. 7: Ruggedness of Doxorubicin Hydrochloride

\begin{tabular}{|l|l|l|l|l|l|}
\hline $\begin{array}{l}\text { Sr. } \\
\text { No. }\end{array}$ & Sample name & $\begin{array}{l}\text { Average } \\
\text { area }\end{array}$ & $\begin{array}{l}\text { Amount of } \\
\text { mg/mL }\end{array}$ & $\begin{array}{l}\text { \% Drug assay from } \\
\text { Method precision }\end{array}$ & $\begin{array}{l}\text { \% } \\
\text { Drug Assay }\end{array}$ \\
\hline 1 & Intermediate Sample 1 & 5592146 & 2.13 & 107.2 & 106.2 \\
\hline 2 & Intermediate Sample 2 & 5645227 & 2.15 & 107.5 & 107.2 \\
\hline 3 & Intermediate Sample 3 & 5611984 & 2.14 & 106.9 & 106.6 \\
\hline 4 & Intermediate Sample 4 & 5621821 & 2.14 & 106.9 & 106.8 \\
\hline 5 & Intermediate Sample 5 & 5679520 & 2.16 & 106 & 107.9 \\
\hline 6 & Intermediate Sample 6 & 5616680 & 2.14 & 107.2 & 106.7 \\
\hline Mean \\
\hline \multicolumn{5}{|l|}{ SD } \\
\hline
\end{tabular}

Table No.8: Forced Degradation of Doxorubicin Hydrochloride

\begin{tabular}{|l|l|l|l|l|l|}
\hline $\begin{array}{l}\text { Sr. } \\
\text { No. }\end{array}$ & Sample treatment condition & $\begin{array}{l}\text { Average } \\
\text { area }\end{array}$ & $\begin{array}{l}\text { Content } \\
\text { in mg }\end{array}$ & $\begin{array}{l}\text { \% labelled } \\
\text { amount }\end{array}$ & $\begin{array}{l}\text { \% } \\
\text { Degradation }\end{array}$ \\
\hline 1 & $\begin{array}{l}\text { 1N Hydrochloric acid, for 30 minutes at } \\
\text { room temperature on Bench top }\end{array}$ & 5688300 & 2.17 & 108.04 & 2.73 \\
\hline 2 & $\begin{array}{l}\text { 0.1N Sodium hydroxide, for less than 1 } \\
\text { minutes at room temperature on Bench top }\end{array}$ & 5229043 & 1.99 & 99.31 & 11.46 \\
\hline 3 & $\begin{array}{l}30 \% \text { Hydrogen Peroxide, for 30 minutes at } \\
\text { room temperature on Bench top }\end{array}$ & 5230949 & 1.99 & 99.35 & 11.42 \\
\hline 4 & $\begin{array}{l}\text { Photo stability chamber 1.2 million LUX } \\
\text { hour and 200 watts hour/m2 for 1 week }\end{array}$ & 5696501 & 2.17 & 108.194 & 2.57 \\
\hline 5 & AS such without degradation & 5832427 & 2.22 & 110.77 & NA \\
\hline
\end{tabular}

Table No.9: Solution stability studies for Doxorubicin Hydrochloride

\begin{tabular}{|l|l|l|l|l|}
\hline \multirow{2}{*}{ Time } & Standard solution & Sample solution & \\
\cline { 2 - 5 } & Area & \% Difference & Area & \% Difference \\
\hline Initial & 5304469 & NA & 5645827 & NA \\
\hline $6 \mathrm{Hr}$. & 5280287 & 0.5 & \multirow{2}{*}{ NA } & \multirow{2}{*}{ NA } \\
\hline $12 \mathrm{Hr}$. & 5237424 & 1.3 & & 0.52 \\
\hline $18 \mathrm{Hr}$. & 5233610 & 1.3 & 5616680 & NA \\
\hline $24 \mathrm{Hr}$. & 5218616 & 1.6 & NA & \\
\hline $30 \mathrm{Hr}$. & 5310972 & 0.1 &
\end{tabular}

\section{Conclusion:}

Liposome as Nano pharmaceuticals is a recent research area that is still far from being fully developed. Thus, numerous nano pharmaceuticals and liposome drug delivery systems have been described for 
pharmaceutical applications but only a few of them are being marketed, although many of these systems are currently in preclinical and clinical development with promising results. The development of analytical methods to control the effectiveness of Liposomal drug delivery systems runs parallel to the development of liposome as nano pharmaceutical and these liposome drug delivery systems so that this analytical area is also very recent and has still not been consolidated. For example, although in recent years many methods have been described for the control of liposomal drug formulations, most of them measure only total drug concentration in the sample and do not distinguish between free and encapsulated drug, which would be desirable to know to establish the real behavior of these formulations, liposomal pharmaceuticals one of the promising drug delivery systems, which can be of potential use in targeting drug delivery systems prepared solvent hydration techniques. The goal of the work presented here is developing and validating a simple, feasible, time saving, cost effective and sensitive reverse-phase high performance liquid Chromatographic method for quantitative determination of total, free and encapsulated drug in Doxorubicin Hydrochloride liposome as nano pharmaceutical. The method was validated as per ICH guidelines and found to be specific, linear and precise and accurate. Therefore, the proposed method can be successfully used for the routine analysis for developmental batches of Doxorubicin Hydrochloride liposomal formulation and used to evaluate free,total and encapsulated drug of commercially available Doxorubicin liposome.

\section{Acknowledgement}

The author thanks to ICICI Knowledge park (IKP), Shameerpet,Hyderbad - 500078, India for providing the Lab facilities to do research work.

\section{References:}

1. G. Redziniak, Path. Biol. Donepezil Hydrochloride, (DH) is a reversible inhibitor of acetylcholinesterase acting in the central nervous system (CNS). 5 (2003) 279.

2. Y. Barenholz, Current Opinion in Colloid \& Interface Science,6 (2001) 66. doi:10.1016/S13590294(00)00090-X

3. S. Gouin, Trends in Food Science and Technology, 15 (2004) 330. doi:10.1016/j.tifs.2003.10.005.

4. G. Gregoriadis, Liposome preparation and related techniques in liposome technology, second ed., CRC Press, Boca Raton, Florida,USA, 1993.

5. A. Go'mez-Hens, J.M. Ferna ndez Romero, Trends in Analytical Chemistry, 24 (2005) 9. doi:10.1016/j.trac.2004.07.017.

6. Angi, R., Solymosi, T., Ötvös, Z., Ordasi, B., Glavinas, H., Filipcsei, G., Heltovics, G., Darvas, F., 2014. Novel continuous flow technology for the development of a nanostructured Aprepitant formulation with improved pharmacokinetic properties,European Journal of Pharmaceutics and Biopharmaceutics, 86, 361-368. doi:10.1016/j.ejpb.2013.10.004.

7. F. Lavelle, M. Bissery, S. Andre, F. Roquet, J. Rio, Seminars in Oncology, 23 (1996) 11-20.

8. R. Garcia-Carbonero, J.G. Supko, Clinical Cancer Research, 8 (2002) 641-661.

9. Ernest S. Kawasaki and Player T A. Nanotechnology, nanomedicine, and the development of new, effective therapies for cancer, Nanomedicine, 2005; 1:101-09. doi:10.1016/j.nano.2005.03.002.

10. Poonthananiwatkul B., Howard RL., Williamson EM., Lim RH.: Cancerpatients taking herbal medicines: A review of clinical purposes, associated factors, and perceptions of benefit or harm, Journal of Ethnopharmacology, 2015; 3:30119-7.

11. Mirtsching B., Cosgriff T., Harker G., Keaton M., Chidiac T., Min M..: A phase II study of weekly nanoparticle albumin-bound paclitaxel with or without trastuzumab in metastatic breast cancer, Clinical Breast Cancer, 2011, (2): 121-8. doi:10.1016/j.clbc.2011.03.007.

12. Linhua Z.,, Yingna H., Mei Y., Cunxian S. Paclitaxel-loaded polymeric nanoparticles based on PCLPEG-PCL: Preparation, in vitro and in vivo evaluation, Journal of Controlled Release, 2011: 152.

13. Fabienne D., Nathalie L., Benoît V., Christine J., Jacqueline M.B., Olivier F., Véronique Paclitaxel loaded PEGylated PLGA-based nanoparticles: In vitro and in vivo evaluatione, Journal of Controlled Release,2009:133, 11-15. doi:10.1016/j.jconrel.2008.09.086.

14. D. Felnerova, J.F. Viret, R. Glu“ ck, C. Moser, Current Opinion in Biotechnology,15 (2004) 518. doi:10.1016/j.copbio.2004.10.005.

15. www.drugbank.com

16. www.sciencedirect.com 
17. www.pubmed.com

18. www.mhra.gov.uk

19. ICH Guideline Q2 (R1)

20. USP 41-NF 36 